American Journal of

Health, Medicine and Nursing Practice (AJHMN)

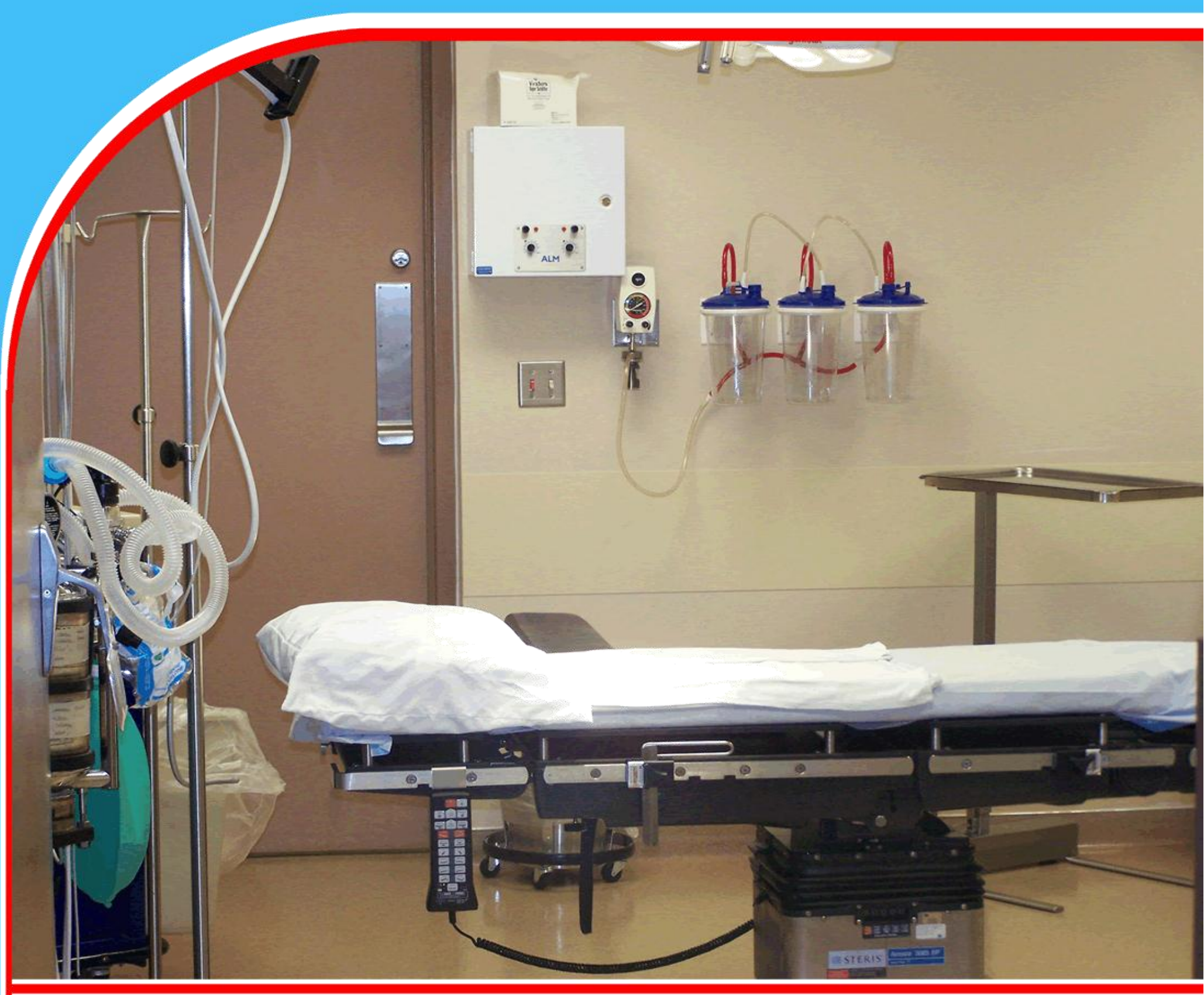

Function of Microscopic Carpal Tunnel Release in Cases Resistant to Conservative Therapy

Jehan Zeb, Dr Muhammad Anwar Ullah, Muhammad Shoaib, Syed Nasir Shah, Walayat Shah, Bakth Jamal, Saad Ali, and Aysha Zafar

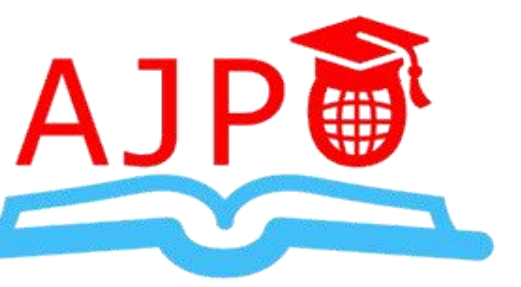




\title{
Function of Microscopic Carpal Tunnel Release in Cases Resistant to Conservative Therapy
}

\author{
${ }^{1}$ Jehan Zeb, ${ }^{2}$ Dr Muhammad Anwar Ullah, ${ }^{3}$ Muhammad Shoaib, ${ }^{4}$ Syed Nasir Shah, \\ ${ }^{5}$ Walayat Shah, ${ }^{6}$ Bakth Jamal, ${ }^{7}$ Saad Ali, and ${ }^{8}$ Aysha Zafar. \\ ${ }^{1,6}$ Consultant Neurosurgeon Dhq Hospital Charsadda \\ ${ }^{2}$ Consultant Neurosurgeon Dhq Hospital Tamergira \\ ${ }^{3}$ Consultant Neurosurgeon Mth Hospital Peshawar \\ ${ }^{4,5}$ Consultant Neurosurgeon Dhq Hosptial Mardan \\ ${ }^{7,8}$ Assistant Professor Neurology. MTI Lady Reading Hospital Peshawar. \\ Corresponding Author: Muhammad Shoaib
}

\begin{abstract}
Purpose: To determine the outcome of microscopic carpal tunnel release in patients with carpal tunnel syndrome who failed to respond to conservative treatment.

Methodology: This descriptive case series was carried at Department of Neurosurgery, D.H.Q Hosptial Charsadda over 1 year from Jan 2019 to Dec 2020, indicate the sampling method used to select the study participants involving 94 patients; both men and women with ages in the range 30-70 years diagnosed of carpal tunnel syndrome who failed to respond to conservative treatment and were planned for surgical release. Microscopic CTS release was performed and outcomes were assessed in terms of improvement in VAS score for wrist pain, symptom severity score and function status scale 3 and 6 months after the surgery. Recurrence of symptoms was also noted. A written informed consent was obtained from every patient. Indicate the method of data collection and data analysis
\end{abstract}

Findings: The mean age of the patients with carpal tunnel syndrome was 41.6 \pm 7.9 years. There was slight female predominance with male to female ratio of 1:2.1. History of diabetes was recorded in $29(31.0 \%)$ patients while $34(37.0 \%)$ patients were obese. Right hand was more frequently involved $(53.0 \%)$ than the left hand $(47.0 \%)$. The mean VAS score for wrist pain reduced from $7.9 \pm 1.2$ at baseline to $1.8 \pm 0.73$ months after the surgery (p-value $<0.001$ ). Similar improvements were also noted in symptom severity score $(3.8 \pm 0.8$ to $1.6 \pm 0.8$; p- value $<0.001)$ and function status scale $(2.7 \pm 0.8$ to $1.5 \pm 0.8$; p-value $<0.001)$ at the end of 3 months after the surgery. Recurrence was not observed in any patient at the end of 6 months follow-up.

Recommendation: Microscopic carpal tunnel release was found to relieve patient's symptoms and improve wrist function yet with minimal scarring and without recurrence which advocates its preferred use in future practice provided necessary surgical skills and hardware are available.

Keywords: Carpal Tunnel Syndrome, Microscopic Release, Recurrence 


\section{INTRODUCTION}

Among the nerve entrapment syndromes affecting the upper limb, carpal tunnel syndrome (CTS) is the most common with an incidence of 1 to 4 persons per 1000 per year and is characterized by compression of median nerve during its passage through carpal tunnel at wrist resulting in characteristic night wrist pain and weakness of grip1. As the median nerve supplied radial three and half fingers, there is diminishing of sensation in these areas ${ }^{2,3}$. In long standing cases one may also see wasting of thenar eminence compared to contralateral side, though one must not forget that many of the patients have bilateral disease1. A number of personal, environmental and occupational factors have been identified which increase the likelihood of CTS particularly thyroid dysfunction, poor glycemic control, pregnancy, inflammatory joint disease and traumatic wrist injuries; fractures as well as repetitive microtrauma e.g. use of electric hammers ${ }^{3}$.

The diagnosis of median nerve entrapment neuropathy is established on history and clinical test namely the phalen's test and durkan's test though these test have their own limitation and are not confirmatory1. The diagnosis is confirmed by nerve conduction studies showing sensory and motor latency in the median nerve at wrist ${ }^{1,2}$. Though there are a lot of treatment options, yet if a patient presents early during the course of disease it is wise to begin with conservative treatment with patient's education to avoid precipitating wrist positions and change of occupation where applicable ${ }^{1,2}$. Night wrist splints can be advised and in resistant cases, oral or locally injected steroids may be beneficial ${ }^{4}$. Surgery is usually reserved as a last resort due to associated complications of scaring and poor cosmesis, potential risk of damage to vital structure and frequent recurrence4. Although, with the advent of new surgical hardware and skills, modifications has been made to conventional surgical release of CTS like mini-incision techniques, yet the subsequent scar and fear of recurrence are main limitations in the widespread acceptability of the surgical release. Therefore the search for the Holy Grail continues ${ }^{1,4}$.

Microscopic surgery has become increasingly popular in the last decade in the fields of sinus ${ }^{5}$, cranial $^{6}$ and spinal ${ }^{6}$ surgery. There are also reports of microscopic release of CTS with promising results. It has been reported that microscopic CTS release is as safe as open surgical CTS release but is superior to the later approach in terms of better cosmesis and decreased frequency of recurrence ${ }^{7-9}$. Conventionally performed open surgical release at our setup. We have recently moved on to the microscopic CTS release. As it is a hardware and operator skill dependent procedure, the purpose of the current study was to evaluate our results in comparison with the already published literature.

\section{MATERIAL AND METHODS}

This was a descriptive case series which was carried out at the Department of Neurosurgery D.H.Q Hosptial Charsadda over a period of 1 year from Jan to Dec 2020. Sample size of 94 cases was calculated with $5 \%$ margin of error and $93 \%$ confidence interval with expected frequency of recurrence to be $5 \%{ }^{10}$ after open surgical release of CTS. 94 diagnosed cases of carpal tunnel syndrome who failed to respond to conservative treatment and were planned for surgical release were included in the study. CTS was diagnosed if 3 or more of the criteria were present 1) Paresthesia in the median nerve territory 2) Nocturnal paresthesia 3) Thenar atrophy 4) Positive Tinel test and 5) Positive Phalen test along with nerve conduction studies showing sensory/motor delay in median nerve across the wrist. Patients suffering from thyroid disorders, 
pregnancy, inflammatory joint disease like rheumatoid arthritis, malignancy and those with history of surgery on the symptomatic wrist were excluded from the study. Also didn't include patients who had recurrence after previous attempt of surgical release.

All the surgeries were performed under anesthesia A transverse 1.0 to $1.5 \mathrm{~cm}$ single incision was made at the level of proximal palmar wrist crease. Palmaris longus tendon was retracted radially. Dilators were used to dilate carpal tunnel associated with base of ring finger and a slotted cannula was placed. Blade was used with microscopic vision to divide transverse carpal ligament. Wound was stitched followed by light padded dressing. It was performed as a day care case and patients were discharged home after the procedure on oral antibiotics and analgesics. Patients were assessed in terms of wrist pain (recorded on visual analogue scale from 0-10) and symptom severity score (SSS) and the function status scale (FSS). These were recorded one day before surgery and then 3 and 6 months after the procedure. Recurrence of symptoms was also looked for. All this information was recorded along with demographic details of the patients like age, gender, BMI, obesity and diabetic status.

Age, BMI, pre- and post-operative pain on visual analogue scale, symptom severity score and the function status scale at 3 and 6 months intervals have been described by mean \pm SD. Paired t-test has been applied to compare follow-up means of VAS, SSS and FSS scores with pre-operative value taking $\mathrm{p} \leq 0.05$ as significant. Gender, obesity and diabetes have been described by frequency and percentage. Data has been stratified for age, gender, obesity and diabetes to address effect modifiers. Post stratification paired t-test has been applied to compare follow-up means of VAS, SSS and FSS scores with pre-operative value across each strata taking $\mathrm{p} \leq 0.05$ as significant.

\section{STUDY RESULTS}

The mean age of the patients was $41.6 \pm 5.9$ years. Observed a slight female predominance among patients with carpal tunnel syndrome with a male to female ratio of 1:2.1. BMI of the patients ranged from $22.1 \mathrm{Kg} / \mathrm{m} 2$ to $34.4 \mathrm{Kg} / \mathrm{m} 2$ with a mean of $25.4 \pm 4.8 \mathrm{Kg} / \mathrm{m} 2$ and $35(37.0 \%)$ patients were obese $(\mathrm{BMI} \geq 30 \mathrm{Kg} / \mathrm{m} 2)$. History of diabetes was recorded in $31(31.0 \%)$ patients as shown in Table 1. The mean VAS score for pain ranged from 5 to 10 with a mean of $7.9 \pm 1.2$ at baseline which decreased significantly to $1.8 \pm 0.7(\mathrm{p}<0.001)$ at 3 months and $1.6 \pm 0.4(\mathrm{p}<0.001)$ at 6 months after the surgery. Similar significant improvement was also noted in the baseline SSS and FSS scores over 3 and 6 post-operative months (Table $2 \&$ Table 3). Didn't observe any recurrence at the end of 6 months follow-up. 
American Journal of Health, Medicine and Nursing Practice

ISSN 2520-4017 (Online)

Vol.6, Issue 4, pp $89-96,2021$

www.ajpojournals.org

Table 1: Demographic features of studied patients.

\begin{tabular}{ll}
\hline Characteristics & Participants $\mathrm{n}=94$ \\
\hline Age (years) & $41.6 \pm 7.9$ \\
Gender & \\
• Male & $30(32.0 \%)$ \\
• Female & $64(68.0 \%)$ \\
Anatomical Side & \\
• Right & $51(53.0 \%)$ \\
• Left & $45(47.0 \%)$ \\
BMI $\left(\mathrm{Kg} / \mathrm{m}^{2}\right)$ & $25.4 \pm 4.8$ \\
• Non-Obese & $61(63.0 \%)$ \\
• Obese & $35(37.0 \%)$ \\
Diabetic & \\
• Yes & $29(31.0 \%)$ \\
• No & $61(69.0 \%)$ \\
\hline
\end{tabular}

Table 2: Comparison of Means of VAS, SSS and FSS with Pre- Operative value at 3 months.

\begin{tabular}{llll}
\hline Follow-up & VAS Score & Symptom Severity Score & Function Status Scale \\
\hline Pre-Operative & $7.9 \pm 1.2$ & $3.8 \pm 0.8$ & $2.7 \pm 0.8$ \\
3 Months after Surgery & $1.8 \pm 0.7$ & $1.6 \pm 0.8$ & $1.5 \pm 0.8$ \\
$\mathrm{p}$ & $<0.001 *$ & $<0.001^{*}$ & $<0.001^{*}$ \\
\hline
\end{tabular}

Paired sample t-test, * the difference between pre- and post- operative value was significant $(\mathrm{p}<0.05)$

Table 3: Comparison of Means of VAS, SSS and FSS with Pre- Operative value at 6 months.

\begin{tabular}{llll}
\hline Follow-up & VAS Score & Symptom Severity Score & Function Status Scale \\
\hline Pre-Operative & $7.9 \pm 1.2$ & $3.8 \pm 0.8$ & $2.7 \pm 0.8$ \\
6 Months after Surgery & $1.6 \pm 0.4$ & $1.5 \pm 0.7$ & $1.3 \pm 0.4$ \\
$\mathrm{p}$ & $<0.001^{*}$ & $<0.001^{*}$ & $<0.001^{*}$ \\
\hline
\end{tabular}

Paired sample t-test, * the difference between pre- and post- operative value was significant $(\mathrm{p}<0.05)$ 
American Journal of Health, Medicine and Nursing Practice

ISSN 2520-4017 (Online)

Vol.6, Issue 4, pp $89-96,2021$

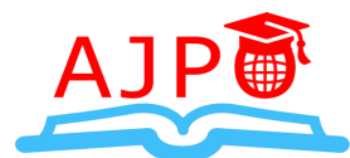

www.ajpojournals.org

\section{DISCUSSION}

Among the broad list of compressive neuropathies, carpal tunnel syndrome is the most common; affecting the median nerve at hand leading to poor grip strength and adversely affects the quality of life1. The symptoms are more marked at night as postural changes in the tunnel volume lead to aggravation of nerve compression ${ }^{1,2}$. That's why disturbance of sleep is phenomenal among these patients ${ }^{1}$. Although surgical release is a common practice in patients who fail to improve with conservative or minimally invasive interventions, yet the subsequent scar, risk of damage to vital structures and recurrence are key factors behind patient's refusal for surgery ${ }^{1,4}$.

Microscopic tunnel release have been developed keeping in view these demerits of open surgery and promises to relieve patient's symptoms yet proving better cosmesis and avoiding damage to vital structures $^{7-9}$. The present study was an internal assessment of microscopic carpal tunnel release at setup.

In the current study, the age of the patients with carpal tunnel syndrome ranged from 22 to 67 years with a mean of $41.6 \pm 5.9$ years. A similar mean age of $39.2 \pm 6.2$ years has been described by Saeed et al., ${ }^{11}$ (2010) among Pakistani patients presenting with CTS at Fauji Foundation Hospital, Rawalpindi while Rashid et al,. ${ }^{12}$ (2016) reported comparable mean age of 43.0 \pm 6.1 years among such patients at Combined Military Hospital, Rawalpindi. In another local study, Amir et al., ${ }^{13}$ (2019) reported slightly higher mean age of $48.5 \pm 12.5$ years among patients presenting with carpal tunnel syndrome at Naseer Teaching Hospital, Peshawar while a relatively younger mean age of $40.5 \pm 22.5$ years has been reported by Aurangzeb et al. ${ }^{14}$ (2018) at Combined Military Hospital Hyderabad. Observation also matches with that of Rouq et al., 15 (2014) who reported similar mean age of 47.8 \pm 5.5 years among Saudi patients with carpal tunnel syndrome. A similar mean age of $44.4 \pm 8.2$ years has been reported by Mardanpour et al., ${ }^{16}$ (2019) among Iranian patients with CTS. Atroshi et al., ${ }^{8}$ (2006) reported similar mean age of $40.0 \pm 20.5$ years among Swedish such patients.

In the current study, we observed that there was a slight female prominence among patients with carpal tunnel syndrome with a male to female ratio of $1: 2.1$. Observation is in line with that of a number of other local studies where Shafiq et al., ${ }^{17}$ (1:2.3), Aurangzeb et al., ${ }^{14}$ (1:2.3) and Saeed et al. ${ }^{11}$ (1:2.3) also reported similar female predominance among such patients at various centers. In other similar local studies, Mansoor et al., ${ }^{18}$ (2017) and Ehsan et al., ${ }^{19}$ (2015) reported comparable female predominance with male to female ratio of 1:1.8 and 1:1.7 respectively. Similar female predominance has also been reported by Mardanpour et al., ${ }^{16}$ (1:2.7) in India, Yagci et al., ${ }^{20}$ (1:2.7) in Turkey and Kalef et al., ${ }^{21}$ (1:2.3) in Brazil.

Thus it can be concluded that carpel tunnel syndrome commonly affects middle aged women. We observed that CTS was more frequent in the right (dominant) hand as compared to left (nondominant) hand (53.0\% vs. $47.0 \%)$. this wiht observation matches with that of Aurangzeb et al.14 who reported involvement of right hand in $51.5 \%$ cases. Saeed et al., ${ }^{11}$ also observed similar higher frequency of CTS in right hand and reported it to be $56.0 \%$ in line with the present study. We already know that CTS results from repeated microtrauma and subsequent changes in the carpal tunnel 3. This explains frequent involvement of right/dominant hand as it is more subjected to these triggering events. 
In the present study, the mean BMI of patients with CTS was $27.4 \pm 4.8 \mathrm{Kg} / \mathrm{m} 2$ and $37.0 \%$ patients were obese $(\mathrm{BMI} \geq 30 \mathrm{Kg} / \mathrm{m} 2) .31 .0 \%$ patients had history of diabetes. This observation matches with that of Yagci et al.20 and Smith et al.9 who reported similar mean BMI of $28.9 \pm 3.8 \mathrm{Kg} / \mathrm{m} 2$ and $26.7 \pm 4.4 \mathrm{Kg} / \mathrm{m} 2$ among such patients. A comparable frequency of diabetes and obesity among CTS patients has been observed by Mansoor et al., ${ }^{18}$ who reported it to be $34.1 \%$ and $33.9 \%$ respectively in local population. Malibary et al., ${ }^{22}$ (2012) reported similar frequency of $35.9 \%$ for diabetes among such patients in KSA.

After the microscopic carpal tunnel release, we observed that the mean VAS score for wrist pain decreased significantly from pre-operative value of $7.9 \pm 1.2$ to $1.8 \pm 0.7$ at 3 months. Our results match with that of Mardanpour et al., ${ }^{16}$ who also reported similar significant decrease $(8.4 \pm 1.4$ to $1.2 \pm 0.6 ; \mathrm{p}<0.001)$ in the mean VAS score for pain 1 month after microscopic carpal tunnel release. Our results are also comparable to those of Okamura et al. ${ }^{7}$ who observed similar reduction in the mean VAS score for wrist pain after microscopic tunnel surgery (7.4 $\pm 2.6 \mathrm{vs}$. $2.5 \pm 2.9 ; \mathrm{p}<0.001)$.

We also assessed the patient outcome in terms of symptom severity score (SSS) and the function status scale (FSS). We observed that SSS improved from 3.8 \pm 0.8 to $1.6 \pm 0.8$ while the FSS improved from $2.7 \pm 0.8$ to $1.5 \pm 0.83$ months after microscopic tunnel release. Our observation matches with that of Smith et al., ${ }^{9}(2020)$ who in a similar recent study reported similar improvement in SSS $(3.5 \pm 0.7$ to $1.7 \pm 0.8 ; \mathrm{p}<0.001)$ and FSS $(2.9 \pm 0.8$ vs. $1.7 \pm 0.9 ; \mathrm{p}<0.001)$ after microscopic carpal tunnel release.

Patient had recurrence over 6 months follow-up. The present study is first of its kind in Pakistani population and adds to the already published international research evidence on the topic. In the present study, microscopic carpal tunnel release was found to relieve patient's symptoms and improve wrist function yet with minimal scarring and without recurrence which advocates its preferred use in future practice provided necessary surgical skills and hardware are available.

The strengths of the present study were its large sample size of 94 cases. Also stratified the results for patient's age, gender, diabetic, and obesity status to minimize bias. A very strong limitation to the present study was that it was a single centre experience and effect of surgical skills on the outcome couldn't be addressed. Moreover the present study was limited by a short follow-up of 6 months. Long term follow-up is required to further establish the efficacy of treatment in terms of recurrence. Such a study addressing these limitations is highly recommended in future research.

\section{CONCLUSION}

In the present study, microscopic carpal tunnel release was found to relieve patient's symptoms and improve wrist function yet with minimal scarring and without recurrence which advocates its preferred use in future practice provided necessary surgical skills and hardware are available. 
American Journal of Health, Medicine and Nursing Practice

ISSN 2520-4017 (Online)

Vol.6, Issue 4, pp $89-96,2021$

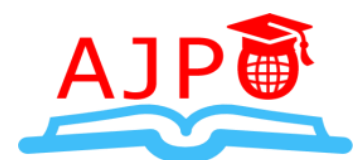

www.ajpojournals.org

\section{REFERENCES}

1. Wipperman J, Goerl K. Carpal Tunnel Syndrome: Diagnosis and management. Am Fam Physician 2016; 94 (12):993-9.

2. Yunoki M, Kanda T, Suzuki K, Uneda A, Hirashita K, Yoshino K. Importance of recognizing carpal tunnel syndrome for neurosurgeons: a review. Neurol Med Chir 2017; 57 (4):172-83. doi:10.2176/nmc.ra.2016-0225

3. Aboonq MS. Pathophysiology of carpal tunnel syndrome. Neurosciences 2015; 20 (1):4-9.

4. Urits I, Gress K, Charipova K, Orhurhu V, Kaye AD, Viswanath O. Recent advances in the understanding and management of carpal tunnel syndrome: a comprehensive review. Curr Pain Headache Rep 2019;23(10):70. doi:10.1007/s11916-019-0811-z

5. Tajudeen BA, Kennedy DW. Thirty years of endoscopic sinus surgery: What have we learned? World J Otorhinolaryngol Head Neck Surg 2017;3(2):115-21. doi:10.1016/j.wjorl.2016.12.001

6. Choi G, Pophale CS, Patel B, Uniyal P. Endoscopic spine surgery. J Korean Neurosurg Soc 2017;60(5):485-97. doi:10.3340/jkns.2017.0203.004

7. Okamura A, Meirelles LM, Fernandes CH, Raduan Neto J, Santos JBG, Faloppa F. Evaluation of patients with carpal tunnel syndrome treated by endoscopic technique. Acta Ortop Bras 2014;22(1):29-33.

8. Atroshi I, Larsson GU, Ornstein E, Hofer M, Johnsson R, Ranstam J. Outcomes of endoscopic surgery compared with open surgery for carpal tunnel syndrome among employed patients: randomised controlled trial. BMJ 2006;332(7556):1473. doi:10.1136/bmj.38863.632789.1F

9. Smith WR, Hirsch DC, Osei-Hwedieh DO, Goitz RJ, Fowler J. A comparison of changes in median nerve cross-sectional area between endoscopic and mini-open carpal tunnel release. J Hand Surg Global Online 2020;2(2):80-3. doi:10.1016/j.jhsg.2019.09.010

10. Jablecki CK, Andary MT, So YT, Wilkins DE, Williams FH. Literature review of the usefulness of nerve conduction studies and electromyography for the evaluation of patients with carpal tunnel syndrome. AAEM Quality Assurance Committee. Muscle Nerve 1993;16(12):1392-414. doi: 10.1002/mus.880161220

11. Saeed MA, Irshad M. Seasonal variation and demographical characteristics of carpal tunnel syndrome in a Pakistani population. J Coll Physicians Surg Pak 2010;20(12):798- 801.

12. Rashid M, Sarwar SU, Haq EU, Islam MZ, Rizvi TA, Ahmad M, et al. Tuberculous tenosynovitis: a cause of carpal tunnel syndrome. J Pak Med Assoc 2006;56(3):116.

13. Amir S,Qadir M, Usman M. Clinical profile of patients with carpal tunnel syndrome. Khyber Med Univ J 2018;10(1):36- 9.

14. Aurangzeb, Akhtar M, Akhtar S. Agreement between ultrasonography and nerve conduction studies in assessment of severity of carpal tunnel syndrome. Paki Armed Forces Med J 2018;68(6):1659-63. 
15. Al Rouq F, Ahmed TS, Meo IM, Al-Drees AM, Meo SA. Distribution of clinical symptoms in carpal tunnel syndrome. J Coll Physicians Surg Pak 2014;24(1):30-3.

16. Mardanpour K, Rahbar M, Mardanpour S. Functional outcomes of 300 carpal tunnel release: $1.5 \mathrm{~cm}$ longitudinal mini-incision. Asian J Neurosurg 2019;14(3):693-7 doi:10.4103/ajns.AJNS_31_17.

17. Shafiq M, Azmat S, Rasheed S, Rafiq A. Carpal tunnel syndrome surgical release with limited incision. Gomal J Med Sci 2016;14:156-9.

18. Mansoor S, Siddiqui M, Mateen F, Saadat S, Khan ZH, Zahid M, et al. Prevalence of obesity in carpal tunnel syndrome patients: a cross-sectional survey. Cureus 2017;9(7):e1519.

19. Ehsan MA, Ehsan S, Arshad HS. Frequency of carpal tunnel syndrome in dentists working in government hospitals of Lahore. Int J Sci Res 2016;5(5):1672-5.

20. Yagci I, Gunduz OH, Sancak S, Agirman M, Mesci E, Akyuz G. Comparative electrophysiological techniques in the diagnosis of carpal tunnel syndrome in patients with diabetic polyneuropathy. Diabetes Res Clin Pract 2010;88(2):157-63. doi:10.1016/j.diabres.2010.02.011

21. Kaleff PR, Lima MS, Fernandes YB, Honorato DJ, Vargas AA, Honorato DC. Carpal tunnel syndrome: treatment with small transverse incision. Arq Neuro-Psiquiatr 2010;68(1):93-7. doi: 10.1590/S0004-282X2010000100020

22. Malibary HM, Al-Najjar AT, Yassen DM, Abuhussain HAA, Radhwi OO, Alfares ZR. Clinical profile of carpal tunnel syndrome in a teaching hospital. Pak J Med Sci 2013;29(1):119-21. 